\title{
O papel das diretoras de escola nas relações entre escolas públicas e famílias populares no contexto de implementação de uma política educacional
}

\section{The role of female school principals in the relationship between public schools and underprivileged families in an educational policy implementation context}

\author{
Edson Diniz Nóbrega Junior*
}

\begin{abstract}
RESUMO
O presente trabalho discute o papel das diretoras de escolas na construção de relações entre escolas públicas e famílias de origem popular que vivem em uma favela da cidade do Rio de Janeiro. Nossa análise levou em conta o contexto de implementação de uma política educacional proposta justamente para aproximar escolas e famílias. Com esse enfoque, queremos iluminar aspectos pouco estudados pela literatura que trata das relações escolasfamílias e da implementação de políticas educacionais. A verdade é que a atuação das diretoras junto às famílias e sua influência na criação de um clima escolar propício a contatos e interações, positivas ou não, acaba sendo negligenciado. Outra questão abordada é o reconhecimento de que o cargo de direção escolar é feminino, e, assim como nas famílias, também são as mulheres as responsáveis pela interação com as escolas, o que faz com que essas relações sejam influenciadas pelo universo das mulheres. E essa marca traz especificidades que procuramos explorar no presente trabalho. Nesse sentido, esperamos contribuir para diminuir uma lacuna no campo da pesquisa que trata das relações escolas públicas e famílias populares. Ao final,
\end{abstract}

* Pontifícia Universidade Católica do Rio de Janeiro. Rio de Janeiro, Rio de Janeiro, Brasil. E-mail: edsondiniznobrega@gmail.com - https://orcid.org/0000-0002-6804-2165 
constatamos que as diretoras de escolas têm papel decisivo na construção de um clima escolar que impacta nas relações das escolas com as famílias.

Palavras-chave: Diretoras de escolas. Relação escola-família. Política educacional. Escola pública. Escolas do Amanhã.

\begin{abstract}
This study discusses the role of female school principals in building relationships between public schools and underprivileged families who live in a slum in the city of Rio de Janeiro. Our analysis considered the context of an educational policy implementation proposal to bring schools and families together. With this approach, we want to illuminate rarely studied aspects in the literature, which deals with school-family relationships and educational policies implementation. The truth is that the performance of the principals with families and their influence in creating a school environment that is an opportunity to contacts and positive interactions - or not - ends up being neglected. Another issue discussed is the recognition that the position of the school principal is female, and since women are also responsible for interacting with schools in families, such relationships are influenced by the women's universe. This pattern brings specificities which we seek to explore in this study. In this sense, we hope to close a gap in the research area regarding public schools and underprivileged families. In the end, we found that the female school principals have a decisive role in creating a school environment that impacts the relationships with families.
\end{abstract}

Keywords: Female school principals. School-family relationship. Educational policy. Public school. Schools of Tomorrow.

\title{
Introdução
}

No cotidiano escolar, é comum ouvirmos que a participação das famílias na educação formal das crianças é fundamental. A parceria "escola-família"l

1 Comumente, a literatura apresenta a fórmula "família-escola" quando trata dessa relação. Invertemos aqui a ordem e a apresentamos como "escola-família", com a representação de uma relação de poder, que tem como polo a escola, pois é ela quem decide não apenas como será a vida escolar das crianças - por extensão de suas famílias -, mas também quem permanece ou não em seus bancos. Entendemos que as famílias não são passivas, reagindo e construindo alternativas para enfrentar essa relação desigual, mas, em última instância, na relação de poder que se estabelece, levam desvantagem. 
é enfatizada como uma das ações mais importantes para o sucesso escolar dos estudantes, e seus responsáveis são chamados a assumir cada vez mais a função de coeducadores.

Essa mesma questão é tratada pela sociologia da educação a partir de várias vertentes (NOGUEIRA, 1998). Assim, o tema das relações escola-família aparece nos estudos sobre as "escolas eficazes" (SOARES; BROKE, 2008), nas pesquisas que tratam diretamente das relações escolas-famílias (ROMANELLI; NOGUEIRA; ZAGO, 2013); (THIN, 2006); (CANEDO, 2018), nas pesquisas que abordam a gestão escolar (PARO, 2016); (CARVALHO; OLIVEIRA; CANEDO, 2018) e nos estudos sobre implementação de políticas educacionais (OLIVEIRA; ABRUCIO, 2018). Está presente ainda em documentos que orientam a educação no país, como na Lei de Diretrizes e Bases da Educação (BRASIL, 1996) e na Constituição de 1988 (BRASIL, 1988). Por fim, em quase todos os programas oficiais de ensino, a recomendação é sempre incentivar a parceria "escola-família" em benefício das crianças.

No entanto, as relações entre escolas e famílias, na maioria dos casos, é marcada por tensões, quando não por conflitos abertos (PARO, 2010; THIN, 2006), o que gera distanciamento e não aproximação. Por isso, embora programas oficiais, profissionais de educação e as próprias famílias reconheçam que a aproximação entre escola e família seja recomendada, a prática não reflete esse desejo.

Tratar dessa questão é especialmente importante quando observamos tal relação a partir das escolas públicas que atendem às classes populares em territórios socialmente vulneráveis como as favelas, por exemplo. Isso porque temos aí relações assimétricas e desigualdades que refletem relações sociais mais gerais, também marcadas por desigualdades socioeconômicas.

O fato é que quando a escola permanece distante do universo de seus estudantes e de suas famílias, isso significa, para estes últimos, prejuízos como reprovações, atraso escolar e abandono. Por isso, investigar mais a fundo as relações entre as escolas públicas e as famílias de origem popular é fundamental para compreendermos os mecanismos que operam o distanciamento entre ambas, bem como para evitar as consequências deste fato.

De modo geral, no que se refere aos agentes concretos que atuam nas duas pontas da relação escola-família, a literatura tem observado as interações a partir dos professores e professoras. Pouco tem se falado sobre o papel de outros agentes escolares, como as diretoras ${ }^{2}$, por exemplo. Talvez isso ocorra porque

2 Adotaremos aqui o gênero feminino para nos referirmos às ocupantes do cargo da direção escolar. Isso porque segundo o questionário de Prova Brasil (BRASIL, 2017), mais de 77\% das direções são ocupadas por mulheres. 
as direções escolares, consideradas parte das estruturas médias nos sistemas de ensino, mantêm um contato mais distante das famílias, sendo acionadas apenas para resolver "problemas" mais sérios. Ou ainda, que a administração central, os agentes escolares e as próprias diretoras reconhecem seu papel limitado às questões administrativas e burocráticas (PARO, 2012).

Discordamos dessa posição. Acreditamos que as diretoras das escolas têm papel fundamental na relação com as famílias e que suas ações podem facilitar ou dificultar a aproximação com os responsáveis pelas crianças. Na verdade, no cotidiano escolar, as diretoras de escolas travam contato direto com as famílias de seus alunos, e são elas as profissionais que fazem uma "ponte" entre a escola e a família. É comum, nas escolas públicas, as diretoras receberem os responsáveis no portão da escola, onde muitas questões escolares são resolvidas informalmente. As diretoras se apresentam para a comunidade interna e externa para profissionais da escola, famílias e bairro como a "cara da escola". Elas encarnam o "espírito" da instituição (BURGOS; CANEGAL, 2011).

Consideramos, assim, que as diretoras exercem forte influência sobre o modo como as escolas se relacionam com as famílias. Seu posicionamento quanto à abertura maior ou menor das escolas e a adoção de uma postura mais cooperativa com as famílias é determinante para a qualidade das relações que se estabelecem. Por isso, as crenças, expectativas e ações das diretoras, a partir do que elas consideram como "participação familiar" e o conceito de "família", orientam, em grande medida, o comportamento da instituição que dirigem.

Nesse sentido, a perspectiva que adotamos neste trabalho é que as diretoras de escolas têm papel fundamental na construção de ações que podem aproximar ou, ao contrário, afastar as escolas públicas e as famílias populares. Na verdade, suas ações ajudam a criar um "clima escolar positivo" e mais favorável - o contrário também é verdadeiro - para a aproximação com as famílias dos estudantes (OLIVEIRA; WALDHELM, 2016).

Embora os pesquisadores ainda não tenham chegado a um consenso sobre quais características compõem o clima escolar, eles concordam que esse é um dos aspectos mais relevantes para o bom funcionamento das escolas. Podemos acrescentar que um bom clima escolar significa maior possibilidade de aproximação entre escola e casa.

No presente trabalho, seguimos a definição adotada por Moro, Vinha e Moraes (2019), que definem o clima escolar como:

(...) o conjunto de percepções e expectativas compartilhadas pelos integrantes da comunidade escolar, decorrente das experiências vividas 
nesse contexto, quanto aos seguintes fatores inter-relacionados: normas, objetivos, valores, relações humanas, organização e estruturas física, pedagógica e administrativa que estão presentes na instituição educativa (MORO; VINHA; MORAES, 2019, p. 317).

Se pudéssemos sintetizar o conceito de clima escolar, diríamos que ele constitui a identidade da escola, que é construída em conjunto, no cotidiano e que todos reconhecem, mesmo que essa definição não esteja inscrita e escrita em um lugar específico. São os "sentidos compartilhados" de que fala Aguerre (2004, p. 55). Porém, mesmo reconhecendo que o clima escolar - que confere a identidade à escola - é uma obra coletiva, relacional, não temos dúvida de que a liderança exercida pelas diretoras de escolas é a base sobre a qual ele se constitui (OLIVEIRA; FONSECA, 2018).

Para observarmos mais de perto o papel das diretoras na aproximação com as famílias, trabalhamos com dados oriundos de uma pesquisa de cunho qualitativo realizada para nosso doutorado no campo da sociologia da educação. Naquela pesquisa, analisamos as relações travadas entre escolas e famílias de origem popular a partir da implementação de uma política educacional em uma favela no município do Rio de Janeiro (DINIZ JUNIOR, 2017).

No entanto, na ocasião, o papel das diretoras de escolas na aproximação com as famílias não foi devidamente explorado porque este não era o objeto principal da pesquisa. Contudo, ao final daquele trabalho, consideramos importante desenvolver a questão entorno das diretoras de escola e de sua contribuição para as relações escolas-famílias. Por isso, a intenção no presente trabalho é desenvolver mais adequadamente esse tema. Ao mesmo tempo, procuramos contribuir para suprir uma lacuna na literatura que trata das relações escola-família.

O presente trabalho está organizado da seguinte forma: em primeiro lugar, apresentamos a discussão acerca das relações entre escolas públicas e famílias de origem popular; depois, há uma apresentação da política educacional implementada em uma favela, que nos permitiu olhar para o papel das diretoras de escola; em seguida, apresentamos a pesquisa que deu origem a este trabalho; na sequência, discutiremos a importância da liderança das diretoras de escolas; e, por fim, abordaremos o papel das diretoras de escolas para as relações escolafamília; encerramos com algumas considerações provisórias. 


\section{As relações escolas-famílias}

Os estudos sobre as relações escola-família apontam para conflitos, tensões e incompreensões acerca do papel de cada uma dessas instituições no processo de educação formal e de socialização das crianças. Ocorre o que Daniel Thin (2006) chama de "lógicas antinômicas", ou seja, escolas públicas e famílias de origem popular possuem maneiras diferentes e mesmo opostas de tratar a educação formal e de socializar as crianças.

Essa antinomia fica patente quando observarmos as famílias populares e o uso do tempo, o modo de estar em grupo, as relações entre os adultos e crianças, a comunicação, a educação etc. Tudo é diferente daquilo que o ambiente escolar tem como norma.

Assim,

Para compreender as relações entre as famílias populares e a escola, [...] [é preciso] levar em conta o fato de que essas relações colocam em jogo maneiras de estar com as crianças, maneiras de examinar as aprendizagens, maneiras de comunicar, ou, ainda, maneiras de regulamentar os comportamentos infantis e juvenis. [...]. Não é, portanto, somente o capital cultural ou o capital escolar que estão em jogo; é o conjunto das práticas socializadoras das famílias que estão implicadas nas relações entre os pais e os professores, e essas práticas devem ser compreendidas por sua distância do modo escolar de socialização, mais do que pelo capital escolar dos pais (THIN, 2006, p. 50).

Outros autores, como Bourdieu e Passeron (2012), por exemplo, denunciam a reprodução cultural praticada na escola como um tipo de "violência simbólica" sofrida pelas crianças de origem popular quando elas chegam às escolas. Nessas instituições, segundo o sociólogo francês, há uma clara inclinação para um determinado tipo de cultura mais próxima das camadas mais abastadas da sociedade. Isso implica em uma desvalorização e no não reconhecimento da cultura das crianças do mundo popular por parte da escola. Por conseguinte, essas crianças e suas famílias têm dificuldades de se ajustar às exigências e expectativas escolares. É por isso que os discursos “oficiais" das escolas apontam para a "inadequação" das crianças de origem popular ao mundo letrado.

Pedro Silva (2003) chama a atenção para as relações "armadilhadas" entre escolas e famílias, que causam tantos empecilhos a uma relação mais profícua. 
Uma dessas armadilhas é o "efeito pigmaleão", que ocorre quando as famílias são julgadas pelos profissionais da escola como boas ou más e, a partir daí, assumem os estereótipos impostos pela escola. Ao final, os responsáveis pelas crianças assumem-se como bons ou maus a partir do julgamento que receberam dos agentes escolares.

Há ainda o discurso das "famílias desestruturadas" (BURGOS; PAIVA, 2009), que ganhou força nos últimos anos nas escolas. Muitos profissionais da educação passaram a justificar os baixos índices de desempenho de seus alunos e alunas a partir da interpretação de que as famílias não tinham estruturas adequadas e negligenciavam a educação escolar.

De acordo com essa visão, tais crianças não têm o apoio necessário para progredir nos estudos, pois vêm de lares "problemáticos", com muitos filhos, casais separados, pais presos ou envolvidos com o crime. No caso das mulheres, elas são acusadas de não serem "boas mães", de serem descuidadas para com a educação escolar ou de delegar para outros parentes, como as avós, por exemplo, suas responsabilidades (BURGOS, 2008). O mais intrigante é que o discurso das famílias desestruturadas não encontra base em nenhuma pesquisa, mas reforça uma outra percepção mais antiga: a da "omissão parental" (LAHIRE, 1997), criada no ambiente escolar para definir as ações - ou a falta destas - por parte das famílias populares.

O que se vê aqui é o desconhecimento, por parte da escola, daquilo que Marcelo Burgos (2008) chamou de "mundo do aluno". Ou seja, as práticas das famílias populares, bem como seus arranjos afetivos e organização interna, não apenas são desconhecidos, como também são alvos de discriminação. Isso porque os referenciais usados pela escola para "julgar" as famílias populares e para dizer quem são os "bons pais" estão de acordo com um modelo de família idealizado e que não encontra referência na realidade da sociedade brasileira contemporânea (ROMANELLI; NOGEIRA; ZAGO, 2013).

Assim, por todas as questões que vimos até aqui, não é difícil compreender porque há uma relação conflituosa que contrapõe escolas públicas e famílias populares, colocando-as como mundos diferentes e distantes. Tal afastamento, por suposto, traz consequências para a carreira escolar das crianças de origem popular, pois dificulta a criação de uma "continuidade" entre o que se aprende na escola e o que se aprende em casa.

Esse fenômeno não atinge as crianças das classes sociais mais abastadas, pois, como ressalta Bourdieu e Passeron, a cultura escolar e a cultura da casa (família) se complementam e mantêm uma relação de proximidade. Ao final, o que temos é uma clara vantagem para crianças socializadas em ambientes mais escolarizados em detrimento daquelas que moram em casas menos escolarizadas. 
Por isso, é tão importante, para pensarmos em termos de equidade de tratamento e de igualdade de chegada - sucesso escolar -, a construção de políticas públicas que possam aproximar as escolas das famílias mais vulneráveis.

A seguir, veremos mais de perto o programa Escolas do Amanhã. Ele foi concebido, em linhas gerais, para melhorar o desempenho de um determinado grupo de escolas públicas e, dentre suas ações, havia uma em especial que se preocupava em construir uma maior aproximação entre escolas e famílias, o Bairro Educador. No entanto, advertimos que nossa intenção não será avaliar o programa, mas tão somente contextualizá-lo para que nos sirva de experiência prática, que permite olhar melhor para a ação das escolas e, em especial, das diretoras.

\section{O programa Escolas do Amanhã e o projeto Bairro Educador em uma favela carioca}

Em 2009, a Secretaria Municipal de Educação do Rio de Janeiro (SMERJ) lançou o programa Escolas do Amanhã (PEA), cujo objetivo principal era investir recursos em 155 escolas com baixos índices educacionais. Tais escolas tinham em comum, além do baixo rendimento educacional, a localização em territórios com altos índices de violência armada. Essas escolas atuavam em 55 bairros considerados "conflagrados", ou seja, territórios onde a violência, praticada por grupos civis que dominam o varejo da venda de drogas, era alta. Além disso, esses territórios apresentavam baixos índices de desenvolvimento humano, concentrando populações pobres e com baixa nível educacional (CENTRO INTEGRADO..., 2013).

Como forma de mitigar os problemas apontados acima, o PEA propunha, além da alocação de maiores insumos nas escolas, o desenvolvimento de ações que pudessem aproximá-las de seus territórios e das famílias de seus estudantes.

Nesse sentido, o PEA desenvolveu o projeto Bairro Educador (BE), cujo orçamento chegou a 12 milhões de reais (CHRISTÓVÃO, 2015) ao longo de três anos. Este projeto claramente seguiu o exemplo de outras cidades brasileiras (CENTRO INTEGRADO..., 2013), inspiradas nos conceitos apresentados “cidades educadoras" (CARTA DAS CIDADES EDUCADORAS, 2020). Nesse documento, as cidades se transformariam em "cidades educadoras", onde seus 
espaços - ateliês, oficinas mecânicas, feiras-livre, salões de beleza etc. - seriam transformados em locais de aprendizagem compartilhados com as escolas.

A ideia dos formuladores da Carta das Cidades Educadoras, portanto, era que a educação se desse em todos os espaços da cidade, muito embora isso não significasse que a escola e sua especificidade educativa fosse "diluída" e perdesse importância. Pelo contrário, o objetivo era envolver todos os cidadãos na atividade educativa, reconhecendo a escola como centro do processo.

No caso do PEA/BE, para construir relações de maior proximidade com as famílias, foi contratada uma organização não governamental especializada na área de educação. Essa instituição produziu materiais de orientação, como o "caderno trilhas educativas" (2013), para auxiliar os profissionais das escolas, ao mesmo tempo em que equipes da ONG participaram do cotidiano escolar no sentido de "intermediar", de acordo com uma das coordenadoras do projeto, as interações entre a escola e as famílias.

Essa ação, no entanto, durou apenas de 2010 a 2013, pois a previsão era que as próprias escolas, após esse período, pudessem assimilar e assumir novas práticas com relação às famílias e ao próprio território, já que também se previa a formação de "redes de apoio" com instituições locais, que constituiriam a base sobre a qual novas relações entre escolas, famílias e territórios seriam construídas. Isso significa, entre outras questões, repensar a própria gestão escolar, já que as parcerias exigiriam uma nova postura das escolas, em que fossem mais abertas e transparentes à comunidade externa e às famílias. Talvez aqui esteja um dos pontos mais sensíveis do projeto Bairro Educador, pois ele mexia com a própria concepção de escola. Seria preciso, por parte dos profissionais da escola, e, principalmente, de sua equipe gestora admitir a maior participação das famílias e das instituições parceiras da escola no território.

Como veremos mais adiante, ficou evidente, a partir das entrevistas com os agentes envolvidos na implementação do PEA/BE, que não foi isso o que aconteceu na prática. $\mathrm{Na}$ entrevista que realizamos com a coordenadora da ONG, encarregada de criar condições de aproximação entre escolas, famílias e territórios, ficou claro o quanto a mediação entre essas instituições é difícil.

A ideia de uma escola fechada e apartada do seu entorno - visto como ameaçadora - ficou evidente na fala de muitos profissionais da educação entrevistados em nossa pesquisa. Talvez essa tenha sido uma das barreiras, junto à falta de acompanhamento do programa por parte da Secretaria Municipal de Educação do Rio de Janeiro (SME-RJ), para que o projeto Bairro Educador não tivesse o sucesso esperado. 


\section{A pesquisa}

A pesquisa de campo que deu origem ao presente estudo durou seis meses, com visitas diárias às escolas para colher depoimentos e observar a dinâmica das interações, formais e informais, entre os profissionais e as famílias. Nesse processo, foram entrevistados os profissionais de educação (professoras, diretoras, coordenadoras pedagógicas, auxiliares de portaria, merendeiras), familiares das crianças, coordenadores do programa Escola do Amanhã e seus formuladores na SME-RJ. Além de entrevistas, foram analisados encontros formais, como as reuniões entre escolas e familiares, e encontros informais, na entrada e saída das crianças, nas festas ou outros eventos que reuniam as diretoras e as famílias.

Para a observação de campo foram escolhidas duas escolas situadas em uma das maiores favelas cariocas porque essas escolas atendiam a públicos semelhantes e tinham desempenho acadêmico também similar. Uma delas havia participado do Programa Escola do Amanhã/Bairro Educador (PEA/BE) e a outra não. A ideia era reconhecer diferenças e semelhanças de atitude em relação às famílias entre a escola que participou da experiência do programa $\mathrm{e}$ a outra que não participou. Nossa expectativa era a de que a escola que havia participado do PEA/BE pudesse ter desenvolvido ações que resultassem em uma maior aproximação com as famílias de seus estudantes.

Podemos caracterizar a escola participante do PEA/BE, para efeitos deste trabalho, como "escola 1", e a escola não participante, como "escola 2". A escola 1 era dirigida, à época, por uma diretora jovem e que estava na direção havia apenas 3 anos. Antes, ela já havia tido experiência na gestão escolar como vice-diretora e em outros cargos. Também teve experiência como professora de crianças do ensino fundamental durante 15 anos. A escola 2, por sua vez, era liderada por uma diretora que estava no cargo há 18 anos e que tinha idade superior à da diretora da escola 1 . A diretora da escola 2 estava na mesma escola há aproximadamente 25 anos.

Ambas afirmaram que mantinham boas relações com a comunidade externa, embora, em vários momentos, tenham feito críticas ao território, que ora era caracterizado como perigoso, ora era visto como "protetor" da escola. Contradições ligadas à localização específica dessas escolas no território. No entanto, o que aproxima as interpretações quanto ao território, uma das maiores favelas da cidade, era a visão de que ali a maioria das pessoas pouco valorizavam a educação escolar. 
Ao final da pesquisa, embora este não fosse o objetivo principal, o que constatamos foi que, a despeito de alguns sucessos localizados, o PEA/ $\mathrm{BE}$ não atingiu suas metas. Não houve melhoria substancial nos resultados escolares na escola 1 quando comparada à escola 2. No entanto, o que mais chamou nossa atenção foi que não conseguimos identificar diferenças significativas entre as escolas pesquisadas no que se referia às relações com as famílias (DINIZ JUNIOR, 2017). Pelo contrário, o que constatamos foi que as distâncias e os conflitos entre as escolas e as famílias eram similares em ambos os casos estudados.

Todavia, chamaram nossa atenção, em particular, os depoimentos dados pelas gestoras das duas escolas, em especial o das diretoras e vicediretoras responsáveis diretamente pela gestão escolar. Esses depoimentos eram semelhantes nas duas escolas e apontavam, com poucas variações, para julgamentos desfavoráveis sobre as famílias populares e a favela. O peso do componente moral na definição do que deveria ser uma "boa família" comprometida com a educação era preponderante.

Desse modo, as famílias eram "classificadas" em boas ou más e assim eram tratadas. Bem como as famílias, o entorno da escola, o território, - a favela também era visto de maneira desfavorável e julgado como um dos responsáveis pelo mal desempenho escolar. A violência, por exemplo, apareceu em quase todos os depoimentos como um dos fatores que mais dificultam o trabalho e impedem bons resultados escolares. Os males eram todos externos.

Por último, ressaltamos que foi durante a pesquisa sobre o PEA/BE e sua intenção de aproximar escolas e famílias que o nosso interesse pelo papel das diretoras nessa relação foi despertado. Assim, nos interessa reconhecer em que medida as diretoras das escolas influenciam na construção de um clima escolar mais favorável ou menos favorável à participação das famílias na escola.

Aí reside a importância de observarmos as diretoras no contexto de implementação do PEA/BE, pois ele nos dá a chance de tratar de uma política que tinha como uma de suas vertentes principais a intenção de aproximar escolas e famílias. Tal movimento exigiu a participação e comprometimento efetivo dos profissionais da escola, em especial das diretoras.

\section{A liderança das diretoras de escola}

Na literatura que trata das escolas eficazes, há uma preocupação em discutir as principais características de escolas que conseguem ter bons resultados 
acadêmicos mesmo em condições adversas (BROKE; SOARES, 2008), como falta de investimentos, de equipamentos e de professores; escolas situadas em bairros com problemas como a violência de grupos civis e que atendem a crianças das classes populares.

Assim, um grupo de pesquisadores, muitos deles preocupados com os resultados do clássico "Relatório Coleman" (BROKE; SOARES, 2008)-depois do qual muitos passaram a acreditar que a escola "não faria a diferença" -, se dispuseram a pesquisar as características de escolas que, contra todas as expectativas, se saíam bem academicamente. Tais estudos apontaram para algumas dessas características: expectativa alta dos professores; incentivos positivos; concentração no ensino e na aprendizagem e parceria casa-escola (SAMMONS, 2008, p. 351)

Porém, quando Sammons (2008) organiza uma "lista" dessas características, coloca na posição número um a "liderança profissional" do diretor, pois, de acordo com ele, o diretor é o "agente-chave" (SAMMONS, 2008 p. 352) das mudanças na escola, pois sua liderança tem impacto sobre toda a vida escolar. Sua administração, seus valores e os objetivos que traça para a escola exercem influência sobre a cultura escolar e sobre os professores o que, por conseguinte, impacta na própria qualidade do ensino oferecido (OLIVEIRA; WALDHELM, 2016).

Fica evidente aqui que o entendimento sobre o conceito de liderança tem a ver com a ideia de que líder é aquela pessoa que influencia, conduz, dirige e constrói consensos capazes de levar em uma determinada direção. No caso das diretoras, tem a ver com o trabalho de mobilizar e influenciar os demais agentes escolares na direção dos objetivos e metas educacionais traçadas e compartilhadas coletivamente (OLIVEIRA; FONSECA, 2018).

De acordo com Sammons (2008), as três principais características de uma diretora que exerce sua liderança são: firmeza e objetividade; enfoque participativo que envolve outros agentes escolares; e autoridade profissional.

As diretoras são elementos centrais na aplicação das políticas educacionais também porque ocupam o escalão intermediário entre os formuladores de políticas (geralmente nas secretarias de educação) e os executores dessas políticas (profissionais das escolas).

São, portanto, o que alguns autores chamam de "burocratas de médio escalão" (LOTTA; PIRES; OLIVEIRA, 2014; OLIVEIRA; ABRUCIO, 2018). De acordo com os estudos de Lotta, Pires e Oliveira esses burocratas - ao contrário da ideia weberiana de um burocrata que apenas obedece e executa ordens - possuem poder de influenciar e moldar as políticas educacionais. A esse processo a autora chama de "discricionariedade" do burocrata.

Por isso, ao tratamos do papel das diretoras de escolas é fundamental reconhecer sua liderança, influência e seu poder de adaptar as políticas 
educacionais ao que elas acham mais conveniente às suas escolas. Obviamente, como essa liderança pode assumir formas diferentes - democrática ou autoritária ou um misto de ambas -, essa influência determina uma maior ou menor abertura da escola (PARO, 2010). É inegável a força que as concepções e ações das diretoras têm no sentido de guiar a escola e definir, assim, "o clima escolar" (CANEDO; MATOS; OLIVEIRA, 2018; MORO, 2018).

Dessa forma, ao analisarmos a literatura sobre as relações entre escolas públicas e famílias populares, sentimos falta de estudos que considerem o papel das diretoras nessa relação.

Assim, para confirmamos a hipótese de que a atuação das diretoras é decisiva para a relação entre escolas e famílias, precisamos responder a algumas indagações, como, por exemplo: como as diretoras enxergam as famílias populares e seus territórios? O que as diretoras consideram como sendo a "participação" ideal das famílias na educação escolar? Como essa interpretação influencia na prática de outros profissionais? De que forma as diretoras contribuem para criar um clima escolar favorável ou não para a aproximação com as famílias?

As respostas a essas perguntas podem ajudar a iluminar áreas ainda pouco exploradas das relações entre as escolas e as famílias. Podem, ainda, ajudar a construir novas relações e mesmo auxiliar a repensar o papel das escolas públicas na vida das crianças mais pobres, assim como o impacto que essas instituições podem ter em territórios como as favelas cariocas. E, claro, todas as questões apontadas acima estão ancoradas no exercício de reflexão sobre qual é o papel das diretoras de escola na relação escola-família.

\section{O papel das diretoras nas relações escolas-famílias}

De acordo com o Censo Escolar (BRASIL, 2020), a maioria das pessoas que ocupam o cargo de direção escolar são mulheres. No estado do Rio de Janeiro, esse percentual chega a, pelo menos, $85 \%$, média mais alta que a dos outros estados brasileiros $(68 \%)$.

Pode-se dizer, assim, que a direção escolar é feminina. De acordo com Canedo e Sales (2018) a maioria das direções escolares no Rio de Janeiro é constituída por mulheres na faixa etária acima dos 50 anos de idade. Esses dados são relevantes, pois, quando se trata de educação escolar no interior das famílias, são as mulheres as mais cobradas por essa atividade, e a maioria dos conflitos com as escolas é administrado por elas (LAHIRE, 1997). 
Desse modo, embora envolva todos os membros das famílias, ao final, na relação escola-família, o protagonismo é feminino. São as mulheres que são chamadas às escolas, e sua ausência nas reuniões e em outros eventos é sempre reclamada como uma falta pela escola.

Assim, a "omissão parental", apontado pelas escolas como um dos maiores problemas na educação escolar das crianças mais vulneráveis é vista como uma "omissão da mulher". Nessa ideia de omissão parental, na verdade um mito, visto que vários estudos comprovam que mesmo famílias mais pobres e menos escolarizadas se preocupam com a educação escolar, há preconceito contra essas famílias, em especial às mulheres (LAHIRE, 1997). Revela-se ainda a persistência de nossa sociedade patriarcal, alicerçada em uma visão conservadora sobre a instituição familiar, que ainda define papéis que separam homens e mulheres, mais do que isso, responsabiliza e cobra das mulheres a exclusividade pelo acompanhamento da educação escolar das crianças, isentando os homens.

De todo modo, esse é um aspecto das relações entre escolas e famílias ainda pouco estudado. Por isso, compreender as representações sobre as famílias populares, sobretudo as que recaem sobre as mulheres, em especial sobre as mães, é importante para entendermos as dinâmicas que regulam as relações entre escolas e famílias.

Em nossa pesquisa, por exemplo, pudemos acompanhar algumas reuniões entre escolas e famílias, nas quais aproximadamente $95 \%$ do público era feminino. Numa dessas reuniões, contamos 78 participantes e apenas um era homem. Invariavelmente, durante os encontros, o tema mais recorrente era sobre a melhor forma de educar as crianças em casa. Os representantes das escolas, quase sempre a diretora, faziam recomendações ou repreensões à forma como se julgava que as crianças estavam sendo educadas pelas mães.

Ainda durante as reuniões, em ambas as escolas estudadas, havia um padrão bem definido. As diretoras falavam a maior parte do tempo enquanto as mães apenas ouviam, sendo os temas todos escolhidos pela escola. Temas que giravam, na maioria das vezes, entorno da cobrança de maior participação dos responsáveis na escola e sobre o controle disciplinar das crianças. Apenas nos minutos finais dessas reuniões, os responsáveis puderam expressar dúvidas e fazer comentários. Havia, portanto, uma assimetria nessa relação: a escola fala, a família - a mãe - ouve. Não há como diminuir as tensões e conflitos se tal estado de coisas permanece.

Desse modo, os momentos formais em que se encontravam as diretoras e suas equipes gestoras com as famílias, representadas quase sempre pelas mulheres, mães, tias, avós, sobrinhas, irmãs, eram momentos frequentemente tensos e de cobranças. O clima não era de diálogo aberto e equilibrado.

Talvez as reuniões escolares sejam os momentos em que a antinomia 
de que nos fala Daniel Thin (2006) se expresse com maior clareza. Contudo, havia mais do que isso. Quase sempre, nas falas, gestos e atitudes era possível perceber a divergência entre escolas e famílias alimentada não apenas por lógicas diferentes de socialização das crianças. O que pudemos constatar foi que a visão das escolas, expressa na fala das diretoras, sobre as famílias de seus alunos e alunas, era que não havia um comprometimento maior com a educação escolar.

Nas entrevistas, tanto na escola 1 quanto na escola 2, as cobranças sobre a presença da família foram constantes. Numa das reuniões entre escolas e famílias a diretora da escola 2 cobrou a presença dos responsáveis na formatura das crianças pequenas. Ela achava um "absurdo" as famílias não estarem presentes nesse evento.

Porém, soubemos depois, pelas mães que se encontravam nessa reunião, que as formaturas aconteciam nos dias de semana, dentro do horário comercial, quando muitos familiares estavam trabalhando ou comprometidos com outras tarefas. Tal quadro não muda quando observamos casos semelhantes na escola participante do PEA/BE.

Esse é mais um exemplo da distância entre o mundo escolar e o mundo das famílias populares. O tempo das atividades é sempre definido pela escola e, embora as famílias se organizem em função dos horários e calendários das escolas, como constatamos em nossas entrevistas com as famílias, há sempre a cobrança pela presença em todos os eventos, mesmo que não haja acordo prévio.

Em uma das entrevistas com a diretora da escola 2 havia a queixa de que as mães chegavam na porta da escola e "nem entravam, largavam o pacote (criança) e iam embora". Essa fala expressa a insatisfação da escola, que vê no gesto de deixar a criança no portão e não entrar para falar com a diretora ou a professora, um verdadeiro desrespeito.

Assim, um gesto repetido cotidianamente por outras famílias de classe média, por exemplo, que não são acusadas de omissão por deixar suas crianças no portão da escola, virava um "descaso" para com a educação quando se tratava de uma família de origem popular. Obviamente, tal constatação estava carregada de uma interpretação negativa sobre as famílias, em especial sobre as mães. Voltamos, assim, à ideia da omissão parental alicerçada na percepção das famílias populares como desestruturas, causa de todos os males e do fraco desempenho escolar.

A questão é saber em que medida essa interpretação, apresentada nas reuniões e praticada no cotidiano, impacta no clima escolar e, por conseguinte, afeta a qualidade da educação oferecida. Moro (2018), por exemplo, ao comentar estudo de Oliveira, revela que $8 \%$ dos resultados do PISA, nos países da OCDE, têm a ver com o clima escolar, demonstrando, assim, a importância deste para os resultados acadêmicos. 
Se admitirmos que o clima escolar constitui o "espírito da escola", ou seja, os valores e as crenças que formam uma visão compartilhada por todos os seus membros - interno e externos (MORO, 2018) - e, ao mesmo tempo, concordarmos com Burgos (2014) quando este afirma que a diretora da escola encarna esse espírito, temos a medida do impacto das atitudes das diretoras em relação às famílias. Isso porque, dentro desse quadro, o que a diretora pensa, diz e faz a respeito das famílias impacta sobre outros profissionais da escola. É como se sua visão servisse de parâmetro para os demais, mesmo que isso seja feito de uma maneira não programada.

Outro aspecto que nos chamou a atenção foi que a maioria dos profissionais entrevistados, as diretoras das escolas à frente, insistiam em separar as funções de escolas e famílias de forma bem definida: cabendo à primeira ensinar os conteúdos escolares e à segunda ensinar "valores" - disciplina, obediência, respeito - como se fosse possível ensinar um sem ensinar o outro.

Assim, de acordo com Diniz Junior (2017) a diretora da escola 1:

A escola como grupo social importante tem como um de seus objetivos trabalhar o convivio social, só que assim, ao meu ver, é trabalhar a interação social, mas não é implementar o valor em cada criança, porque eu acho que os valores deveriam ser implementados em cada criança pela família $[\ldots]$

Há outro componente importante para a formação do julgamento que as diretoras das escolas, independentemente se participaram ou não do PEA/BE, faziam das famílias: o território.

Como ambas as escolas se localizavam em uma das maiores favelas da zona norte da cidade, dominada por grupos civis armados, havia sempre um estigma sobre as famílias que as identificava com as características negativas desse território. Por isso, as famílias eram vistas como desinteressadas e muitas daquelas rotuladas como "problemáticas", geralmente as famílias das crianças com maiores dificuldades escolares, eram associadas à violência e mesmo ao mundo do crime.

Nas entrevistas, por exemplo, algumas professoras disseram que a função principal da escola era a de "acolher" as crianças, como se fossem um refúgio do mundo violento além muros. Sua função seria muito mais de "proteger e dar amor" do que ensinar conteúdos curriculares, por exemplo. Essa interpretação foi endossada diversas vezes pelas equipes de direção. 
Nesse sentido, ficou claro que a interpretação que as diretoras das escolas, independentemente se suas escolas faziam parte da política educacional cujo objetivo era aproximar a escola das famílias, têm peso e direcionam a instituição escolar para uma maior ou menor proximidade com as famílias.

Reconhecer, portanto, que o que pensam e como agem as diretoras das escolas com relação às famílias é fundamental para entender boa parte das questões que envolvem as relações escolas-famílias. Foi a essa conclusão que pudemos chegar ao final de nossa pesquisa, ou seja, a diretora é decisiva para as relações entres escolas e famílias. Se sua atitude é positiva e as expectativas são altas, as chances de boas relações com as famílias acontecerem, aumentam.

No entanto, o contrário também é verdadeiro, ou seja, se as diretoras mantêm postura desconfiada e reativa às famílias, a escola se fecha e a participação das famílias fica inviabilizada. Este último cenário foi o que encontramos nas escolas pesquisadas.

Por isso, qualquer política educacional que se disponha a enfrentar os problemas que ocorrem na relação entre as duas maiores instituições socializadoras por excelência - escolas e famílias - precisa levar em consideração que as diretoras de escolas, mais do que gestoras administrativas, são lideranças influentes e que o clima escolar depende em grande medida de sua visão e de suas ações.

Diretoras e mães são o centro das relações entre escolas e famílias, e aproximá-las é um desafio que os formuladores de políticas educacionais precisam enfrentar. E isso se faz com investimento, planejamento e com escuta atenta para as razões de um conflito que impede, em boa medida, o progresso de alunos menos favorecidos. Enfrentar esse drama é, portanto, lutar contra desigualdades educacionais que se convertem em desigualdades sociais.

\section{Considerações provisórias}

O tema das relações escolas-famílias é um dos mais caros à educação e ao desenvolvimento de políticas educacionais preocupadas em diminuir desigualdades educacionais. Isso porque, embora os meandros dessa relação precisem ser mais bem estudados, fica evidente que, quando essa cooperação não acontece e os conflitos se tornam mais intensos, os resultados são prejudiciais, principalmente para as crianças e famílias mais vulneráveis.

Outra questão que merece atenção é reconhecer que a relação escolafamília, antes de tudo, é uma relação assimétrica e de poder. Primeiramente, 
porque é a escola quem sanciona e permite que as carreiras escolares das crianças de famílias populares tenham sucesso e longevidade. Depois, porque, como apontava Bourdieu e Passeron, há uma reprodução das desigualdades no interior da escola que recai sobre as crianças das classes populares que não possuem capital cultural mais elevado, justamente o que a escola valoriza.

Obviamente, isso se deve ao fato de que as escolas não são instituições "neutras". Pelo contrário, elas carregam e reproduzem as relações sociais mais gerais e isso significa, em muitos momentos, naturalizar as desigualdades socais e educacionais.

Contudo, essas questões não são desconhecidas dos pesquisadores que tratam do tema das relações escolas-famílias e muito menos no campo da sociologia da educação. Assim, a novidade do presente trabalho reside no fato de colocarmos no centro do debate o papel das diretoras de escola na relação escola-família, principalmente com relação às mulheres, em especial às mães.

Como vimos, as ações das diretoras e a maneira como "interpretam" as famílias de seus estudantes têm impacto na criação de um clima escolar mais ou menos propício para que as relações aconteçam de maneira produtiva. São as diretoras que demarcam e garantem os limites entre escolas e famílias, e isso é compartilhado com os demais profissionais das escolas. Foi o que pudemos observar no caso das diretoras de escola apresentadas neste trabalho, que ao não construírem um clima escolar favorável à participação das famílias, mantiveram suas escolas afastadas. E, mesmo que sustentassem o discurso de abertura da escola, na prática, isso não aconteceu.

Por isso, qualquer política educacional que pretenda aproximar as escolas e as famílias precisa levar em conta o papel das diretoras das escolas públicas. Se essas profissionais encampam a ideia de que uma cooperação efetiva entre suas escolas e as famílias é importante e pode, de fato, ser boa para todos, principalmente para a crianças, as chances de sucesso escolar aumentam substancialmente.

Assim, investir em programas que ajudem a diminuir a distância entre escolas e famílias ao estabelecer uma ponte entre elas, passa pelo reconhecimento da importância do papel da diretora escolar no processo. Esse pode ser um dos caminhos para superar os enormes desafios que as escolas públicas enfrentam nos territórios mais vulneráveis da cidade. 


\section{REFERÊNCIAS}

AGUERRE, Tabaré Fernández. Clima organizacional en las escuelas: un enfoque comparativo para México y Uruguay. REICE - Revista Electrónica Iberoamericana sobre Calidad, Eficacia y Cambio en Educación. [S. l.], v. 2, n. 2, p. 43-68, 2004. Disponível em: https://revistas.uam.es/reice/article/view/5548. Acesso em: 17 ago. 2021.

BRASIL. Presidência da República. Lei nº.394, de 20 de dezembro de 1996. Estabelece as diretrizes e bases da educação nacional. Brasília, DF: Presidência da República, 20 dez. 1996. Disponível em: http://www.planalto.gov.br/ccivil_03/leis/L9394.htm. Acesso em: 23 mar. 2021.

BRASIL. Instituto Nacional de Estudos e Pesquisas Educacionais Anísio Teixeira (INEP). Microdados do Sistema de Avaliação da Educação Básica de 2017 são divulgados. Brasília, DF: INEP, 2018. Disponível em: https://download.inep.gov.br/microdados/ microdados_saeb_2017.zip. Acesso em: 20 ago. 2021.

BRASIL. Instituto Nacional de Estudos e Pesquisas Educacionais Anísio Teixeira (INEP). Resumo Técnico: Censo da Educação Básica Estadual 2019. Brasília, DF: INEP, 2020. Disponível em: https:/download.inep.gov.br/publicacoes/institucionais/ estatisticas_e_indicadores/resumo_tecnico_do_estado_do_rio_de_janeiro_censo_da_ educacao_basica_2019.pdf. Acesso em: 20 ago. 2021.

BOURDIEU, Pierre; PASSERON, Jean Claude. A reprodução. Elementos para uma teoria do sistema de ensino. Rio de Janeiro: Vozes, 2012.

BURGOS, Marcelo Baumann; CANEGAL, Ana Carolina. Diretores escolares em um contexto de reforma da educação. Revista pesquisa e debate em educação. Juiz de Fora. v. 1, n. 1, p. 14-36, 2011.

BURGOS, Marcelo Baumann (org.). A escola e o mundo do aluno: estudos sobre a construção social do aluno e o papel institucional da escola. Rio de Janeiro: Garamond, 2014.

BURGOS, Marcelo Bauman; PAIVA, Angela Randolpho (org.). A Escola e a Favela. Rio de Janeiro: PUC/Rio, 2009.

CANEDO, Maria Luiza. Família e escola: interações densas e tensas. Curitiba: Appris, 2018.

CANEDO, Maria Luiza; SALES; Ana Luiza Honorato. Desafios atuais da gestão escolar: percepções dos diretores da rede municipal do Rio de Janeiro. In: CARVALHO, Cynthia Paes; OLIVEIRA, Ana Cristina Prado de; CANEDO, Maria Kuiza (org.). Gestão escolar e qualidade da educação: caminhos e horizontes de pesquisa. Curitiba: CRV, 2018. p. 61-77.

CARTADAS CIDADES EDUCADORAS. [S. l.: S. n.], 2004. Disponível em: http://www. fpce.up.pt/ciie/OCE/docs/Cartadascidadeseducadoras.pdf. Acesso em: 10 dez. 2020.

CARVALHO, Cynthia Paes; OLIVEIRA, Ana Cristina Prado de; CANEDO, Maira Luiza (org.). Gestão e qualidade da educação: caminhos e horizontes de pesquisa. Curitiba: CRV, 2018. 
CENTRO INTEGRADO de Estudos e Desenvolvimento Sustentável (CIEDS). Traçado Metodológico: um caminho percorrido. Rio de Janeiro: CIEDS, 2013. Disponível em: https://www.cieds.org.br/docs/tracado-metodologico.pdf. Acesso em: 17 ago. 2021.

CHRISTÓVÃO, Ana Carolina. Compensação educacional na cidade do Rio de Janeiro: estudando o Programa Escolas do Amanhã. Porto Alegre: CONGRESSO BRASILEIRO DE SOCIOLOGIA, 27., 2015, Porto Alegre. Anais [...]. Porto Alegre: SBS, 2015.

DINIZ JUNIOR, Edson Nóbrega. A relação escola-familia-vizinhança na favela da Maré e o Programa Escolas do Amanhã/Bairro Educador. 2017. Tese (Doutorado em Educação) - Pontifícia Universidade Católica do Rio de Janeiro, Rio de Janeiro, 2017. Disponível em: https:/www2.dbp.puc-rio.br/pergamum/tesesabertas/1311687_2017_completo.pdf. Acesso em: 17 ago. 2021.

LAHIRE, Bernad. Sucesso escolar nos meios populares: as razões do improvável. São Paulo: Papirus, 1997.

LOTTA, Gabriela Spanghero; PIRES, Roberto Rocha Coelho; OLIVEIRA, Vanessa Elias. Burocratas de médio escalão: novos olhares sobre velhos atores da produção de políticas públicas. Revista do Serviço Público. Brasília, v. 65, n. 4, p. 463-492, 2014. Disponível em: http://seer.enap.gov.br/index.php/RSP/article/view/562/516. Acesso em: 17 ago. 2021.

MORO, Adriano. A construção e as evidências de validade de instrumentos de medida para avaliar o clima escolar. 2018. Tese (Doutorado em Educação) - Universidade Estadual de Campinas, Campinas, 2018.

MORO, Adriano; VINHA, Telma Pileggi; MORAIS, Alessandra de. Avaliação do clima escolar: construção e validação de instrumentos de medida. Caderno de Pesquisa, São Paulo, v. 49, n. 172, p. 312-335, abr./jun. 2019.

NOGUEIRA, Maria. Alice. Relação família-escola: novo objeto na sociologia da educação. Paidéia, Ribeirão Preto, v. 8, n. 14/15, p. 91-103, 1998.

OLIVEIRA, Ana Cristina Prado de; WALDHELM, Andrea Paula Souza. Liderança do diretor, clima escolar e desempenho dos alunos: Qual a relação? Ensaio, Rio de Janeiro, v. 24, n. 93, p. 824-844, 2016.

OLIVEIRA, Ana Cristina Prado de; FONSECA, Marcela Paquelet. A gestão escolar e a contrução do clima escolar. In: CARVALHO, Cynthia Paes; OLIVEIRA, Ana Cristina Prado de; CANEDO, Maria Kuiza (org.). Gestão escolar e qualidade da educação: caminhos e horizontes de pesquisa. Curitiba: CRV, 2018. p. 119-131.

OLIVEIRA, Vanessa Elias de; ABRUCIO, Fernando Luiz. Burocracia de médio escalão e diretores de escola: um novo olhar sobre o conceito. In: PIRES, Roberto; LOTTA, Gabriela; OLIVEIRA, Elias de (org.). Burocracia e políticas públicas no Brasil: interseções analíticas. Brasília, DF: Ipea: Enap, 2018. p. 23-57. 
PARO, Vitor Henrique. A educação, a política e a administração: Refexões sobre a prática do diretor de escola. Educação e Pesquisa, São Paulo, v. 36, n. 3, p. 763-778, 2010.

PARO, Vitor Henrique. Administração escolar: introdução crítica. 17. ed. São Paulo: Cortez, 2012.

ROMANELLI, Geraldo; NOGUEIRA, Maira Alice; ZAGO, Nadir (org.). Família e escola: novas perspectivas de análise. Petrópolis, RJ: Vozes, 2013.

SAMMONS, Pam. As características-chave das escolas eficazes. In: SOARES. José Francisco; BROKE, Nigel (org.). Pesquisa em eficácia escolar: origem e trajetórias. Belo Horizonte: Editora UFMG, 2008. p. 335-387.

SILVA, Pedro. Escola-familia, uma relação armadilhada: interculturalidade e relações de poder. Santa Maria da Fé: Edições Afrontamento, 2003.

SOARES, José Francisco; BROKE, Nigel (org.). Pesquisa em eficácia escolar: origem e trajetórias. Belo Horizonte: Editora UFMG, 2008.

THIN, Daniel. Para uma análise das relações entre famílias populares e escola: confrontação entre lógicas socializadoras. Revista Brasileira de Educação, Rio de Janeiro, v. 11, n. 32, p. 211-236, 2006.

Texto recebido em 04/12/2020.

Texto aprovado em 21/06/2021. 